\title{
Análise Longitudinal de Músculos Sóleos, de Ratos, Submetidos a Alongamento Passivo com Uso Prévio de Ultrassom Terapêutico
}

\author{
Longitudinal Analysis of Soleus Muscles of rats Submitted to Passive \\ Stretching With Previous Use of Therapeutic Ultrasound
}

APARELHO LOCOMOTOR NO EXERCÍCIO E NO ESPORTE

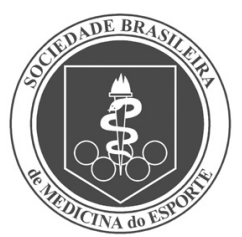

Artigo Original
Gladson Ricardo Flor Bertolini', Cláudio Henrique Barbieri², Nilton Mazzer $^{3}$

1. Universidade Estadual do Oeste do Paraná - Campus de Cascavel - PR

2. Faculdade de Medicina de Ribeirão Preto - Universidade de São Paulo - SP.

3. Faculdade de Medicina de Ribeirão Preto - Universidade de São Paulo - SP.

Endereço para correspondência: Gladson Ricardo Flor Bertolini, Travessa Sebastião Pereira de Camargo, 69, Jardim Padovani - 85803-328 - Cascavel, PR. E-mail: gladson_ricardo@yahoo.com.br

Submetido em 22/04/2008 Versão final recebida em 27/06/2008 Aceito em 24/10/2008

\begin{abstract}
RESUMO
O alongamento muscular é muito difundido entre atletas e pessoas envolvidas em atividades físicas, além de procedimento rotineiro em clínicas de fisioterapia, principalmente visando o aumento na flexibilidade. 0 ultrassom terapêutico possui ações térmicas e atérmicas, o que gera possibilidades de aumento de extensibilidade tecidual e metabolismo celular, e pode auxiliar nos efeitos anabólicos do alongamento estático. 0 objetivo deste estudo foi analisar os efeitos do alongamento passivo estático em músculo sóleo esquerdo (MSE) de ratos, associado ao uso do ultrassom terapêutico, sobre alterações longitudinais do tecido muscular. Foram utilizados 42 ratos Wistar, divididos em grupos tratados com ultrassom terapêutico com doses térmicas e não, e subsequente alongamento estático em três séries de 30s, além de grupos apenas tratados com ultrassom ou alongados, durante 15 dias de tratamento. Foram comparadas as variações encontradas entre o MSE e o MSD de cada grupo. As variáveis foram: comprimento muscular, estimativa de sarcômeros em série na fibra e ao longo do músculo, e comprimento de sarcômeros. Os resultados das variáveis analisadas apontaram alterações no comprimento muscular de repouso nos grupos em que foi associado ultrassom terapêutico, em dose térmica, ao alongamento estático, mas para as outras variáveis analisadas não houve diferenças significativas. Conclui-se que o alongamento passivo estático e o uso associado do ultrassom terapêutico, de forma térmica, produziram apenas aumento no comprimento muscular em repouso.
\end{abstract}

Palavras-chave: ultrassom, músculo esquelético, sarcômeros.

\begin{abstract}
Muscular stretching is much diffused among athletes and people involved in physical activities, besides being a routine procedure in physiotherapy clinics, mainly aiming at flexibility increase. The therapeutic ultrasound possesses thermal and non-thermal effects, which generate possibilities of tissue extensibility and cellular metabolism increase and can aid in static stretching anabolic effects. The aim of this study was to analyze the static passive stretching effects in left soleus muscle (LSM) of rats, associated to the therapeutic ultrasound use on muscular tissue longitudinal alterations. Forty-two Wistar rats, divided in therapeutic ultrasound treated groups, with thermal and non-thermal doses, and subsequent static stretching in 3 sets of $30 \mathrm{~s}$, besides groups just treated with ultrasound or stretched, for 15 days were used. The variations found between LSM and RSM of each group were compared. The variables were: muscular length, serial sarcomere estimation in the fiber and along the muscle, and sarcomere length. The analyzed variables results showed alterations in rest muscular length in the groups with therapeutic ultrasound in thermal dose associated to static stretching. However, there were not significant differences for the other analyzed variables. It is concluded that static passive stretching associated to therapeutic ultrasound in thermal dose just produced increase in rest muscular length.
\end{abstract}

Keywords: ultrasound, skeletal muscle, sarcomere.

\section{INTRODUÇÃO}

A prática dos exercícios de alongamento é muito difundida entre atletas e pessoas envolvidas em atividades físicas (1), além de procedimento rotineiro em clínicas de fisioterapia ${ }^{(2)}$. O aumento na amplitude de movimento (ADM), a redução no risco de lesões musculoarticulares e a melhora no desempenho físico são alguns dos principais motivos relacionados a sua inclusão como forma de tratamento ${ }^{(3)}$, mas, segundo Shrier( ${ }^{(4)}$, o desempenho é melhorado apenas com uso de sessões periódicas de alongamento, não ocorrendo em sessões únicas.

Visando o ganho de flexibilidade em humanos, há importantes relatos de ganho de ADM, quando programas de alongamento mus- cular, diários, são instaurados para indivíduos sadios, jovens ou idosos; o tempo de manutenção do alongamento varia entre 15 e 60s, com uma a cinco séries, entre quatro e oito semanas ${ }^{(5,6)}$.

O alongamento passivo é transmitido progressivamente na fibra muscular, desde a superfície até a subunidade contrátil do músculo. Após o estímulo atingir o sarcômero, essa informação relacionada com o comprimento da fibra é transmitida para o núcleo da célula muscular, onde o DNA é transcrito; logo há acúmulo de RNAm nas terminações dos músculos e inicia-se o processo para síntese de proteínas que darão origem a um novo sarcômero( ${ }^{(7)}$.

O ultrassom terapêutico possui ações físicas, biofísicas e terapêuticas, sendo alvo de investigações desde a introdução deste recurso, há 
mais de 50 anos, vista sua importante ação metabólica em processos de reparo tecidual e também de lesão celular, tendo ainda alguns efeitos controversos na literatura ${ }^{(8)}$.

Quando as ondas ultrassônicas se deslocam nos tecidos, parte é absorvida; isso conduz à geração de calor devido à vibração molecular; essa elevação de temperatura possibilita o aumento da extensibilidade do tecido conjuntivo ${ }^{(9)}$. Contudo, Young ${ }^{(10)}$ relata que com doses abaixo de $0,5 \mathrm{~W} / \mathrm{cm}^{2}$ agem apenas os efeitos não térmicos do ultrassom, o que conduz a incrementos na síntese proteica, aumentando assim a síntese de colágeno e, dessa forma, o tecido conjuntivo se tornaria mais forte e deformável(9,11).

A literatura apresenta relatos do uso do ultrassom, visando o ganho de ADM, em indivíduos saudáveis, com indícios de efeitos vantajosos com respeito a outras metodologias para ganho de extensibilidade ${ }^{(12-14)}$.

Apesar de o alongamento estático ser incorporado dentro de exercícios de aquecimento, treinamento e programas de reabilitação(6), e duas ou três sessões semanais de alongamento muscular, em curta duração, sejam frequentemente recomendadas, não há consenso sobre o tipo de mudanças que ocorrem nas fibras do músculo esquelético submetido a sessões periódicas de alongamento ${ }^{(5)}$, bem como as alterações que o ultrassom pode produzir e sobre possíveis efeitos sarcomerogênicos do alongamento estático.

Dessa forma, o objetivo deste estudo foi analisar os efeitos do alongamento passivo estático em músculo sóleo, de ratos, associado ao uso do ultrassom terapêutico, sobre alterações longitudinais do tecido muscular, como: comprimento muscular e de sarcômeros em repouso, estimativa da quantidade de sarcômeros em série ao longo da fibra e do músculo.

\section{MÉTODOS}

\section{Animais e grupos experimentais}

Neste estudo foram utilizados 42 ratos machos Wistar, com idade de $12 \pm 2$ semanas, obtidos no Biotério Central da Universidade Estadual do Oeste do Paraná - Unioeste. Os animais foram agrupados e mantidos em gaiolas plásticas, com três animais cada, em condições ambientais controladas (luminosidade: 12 horas de ciclo claro/escuro; temperatura: $25^{\circ} \pm 2{ }^{\circ}$ ), com livre acesso à água e ração. 0 estudo foi conduzido segundo as normas internacionais de ética na experimentação animal (15) e foi aprovado pela CETEA da Faculdade de Medicina de Ribeirão Preto da Universidade de São Paulo.

Os animais foram divididos aleatoriamente em três grupos:

Grupo A ( $n=18)$ : recebeu aplicação de ultrassom terapêutico, na região do músculo tríceps sural, na pata posterior esquerda, com posterior alongamento passivo estático, sendo subdividido de acordo com a dose aplicada em:

GA1: dosimetria de $0,2 \mathrm{~W} / \mathrm{cm}^{2}$ contínuo (seis animais);

GA2: dosimetria de $0,5 \mathrm{~W} / \mathrm{cm}^{2}$ contínuo (seis animais);

GA3: dosimetria de $1,0 \mathrm{~W} / \mathrm{cm}^{2}$ contínuo (seis animais).

Grupo B ( $n=18)$ : serviu como controle, sendo realizada a terapia com ultrassom, porém sem o estresse de alongamento passivo, com a dosimetria seguinte:

GB1: dosimetria de $0,2 \mathrm{~W} / \mathrm{cm}^{2}$ contínuo (seis animais);

GB2: dosimetria de $0,5 \mathrm{~W} / \mathrm{cm}^{2}$ contínuo (seis animais);

GB3: dosimetria de $1,0 \mathrm{~W} / \mathrm{cm}^{2}$ contínuo (seis animais).

Grupo C (GC, seis animais): neste grupo não houve aplicação do ultrassom terapêutico, apenas simulação, com subsequente alongamento passivo durante três semanas.

\section{Protocolo de aplicação de ultrassom terapêutico}

O equipamento de ultrassom utilizado foi o Sonopulse S-33 da marca Ibramed ${ }^{\circledR}$, com cabeçote de $1,0 \mathrm{~cm}^{2}$ de ERA, frequência de $1 \mathrm{MHz}$, o qual foi previamente aferido e calibrado. Para se efetuar a técnica de aplicação de ultrassom terapêutico e alongamento no músculo sóleo, os animais foram previamente anestesiados com xilazina $(12 \mathrm{mg} / \mathrm{kg}$ ) e quetamina (95mg/kg). Foram posicionados em decúbito lateral, com o transdutor de ultrassom em contato com a região do tríceps sural esquerdo por meio de gel hidrossolúvel; realizou-se aplicação de ultrassom, em movimentos circulares lentos, em 2 a $3 \mathrm{~cm} / \mathrm{s}$, durante 5 min, para evitar fenômenos de cavitação instável e aquecimento excessivo(16).

Nos grupos que não receberam aplicação de ultrassom, os animais foram anestesiados e o transdutor posicionado de forma semelhante à dos demais sem, contudo, haver aplicação do ultrassom. O protocolo foi repetido diariamente, por três semanas, excetuando-se os finais de semana, perfazendo 15 dias de terapia.

\section{Protocolo de alongamento muscular}

Após a aplicação ou simulação do ultrassom, os animais foram submetidos ao estresse de alongamento de sóleo esquerdo. Para tanto, a articulação tibiotársica foi mantida em flexão dorsal máxima, manualmente, durante 30s, e posterior relaxamento durante 30s, sendo repetido o alongamento mais duas vezes e intercalados por 30 s de repouso; a articulação do joelho permaneceu em $90^{\circ}$ de flexão para evitar interferências dos gastrocnêmios durante o alongamento. Para os grupos em que não se realizou alongamento, houve apenas o posicionamento manual passivo do joelho em 90\%.

\section{Dissecação dos músculos}

Após 24 horas do término do experimento, os animais foram anestesiados e os músculos sóleos direito e esquerdo dissecados e gotejados com solução fisiológica de $\mathrm{NaCl}(0,9 \%)$; os animais eram, então, submetidos à eutanásia por decapitação em guilhotina. Posteriormente, os músculos foram posicionados sobre papel-alumínio, no comprimento de repouso, e avaliado o maior comprimento por meio de paquímetro. Posteriormente, foram imersos em solução de formol (10\%) por 3h e parte colocada em ácido nítrico (30\%) para hidrólise do tecido conjuntivo, permanecendo neste por 48h, sendo, em seguida, armazenados em solução de glicerol (50\%).

\section{Estimativa de sarcômeros em série e comprimento do sarcômero}

Para a confecção das lâminas histológicas, as fibras musculares foram isoladas com uso de pinças de pontas finas, colocando-se o músculo em uma placa de Petri e visualização com auxílio de lupa. Após a retirada das fibras, estas foram montadas em lâmina histológica contendo verniz; em seguida, foram protegidas com uma lamínula para posterior observação em microscópio de luz.

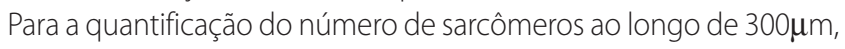
numa fibra muscular foi selecionada a região medial e a contagem realizada sempre pelo mesmo examinador, visando evitar tendências. Em todas as lâminas foram analisadas cinco fibras, através da conta-

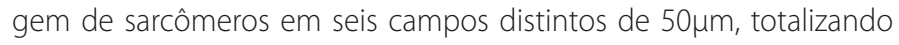
300 $\mu$ m por fibra.

Para realizar a análise utilizou-se um microscópio de luz comum (Olympus), com objetiva de 60 vezes em imersão, acoplado a um aparelho de televisão de 29 polegadas, o qual teve seu tubo de imagem previamente aferido para a distância correspondente a 50um. Posteriormente, por regra de três simples, estimou-se a quantidade de sarcômeros em série na fibra muscular e ao longo do músculo; em seguida, realizou-se a estimativa de comprimento de sarcômeros, dividindo a quantidade encontrada na fibra pelo comprimento da mesma(17).

\section{Análise estatística}

Os dados foram analisados através da estatística descritiva e dentro do grupo (direito e esquerdo) foi utilizado o teste $t$ de Student pareado, com nível de significância de $a=5 \%$. 


\section{RESULTADOS}

\section{Comprimento muscular}

Para comprimento muscular, apenas GA2 e GA3 apresentaram diferenças estatisticamente significativas, como pode ser observado na tabela 1.

Tabela 1. Resultados do comprimento muscular, de acordo o grupo avaliado, comparando os valores do músculo sóleo direito (MSD) com os do músculo sóleo esquerdo (MSE)

\begin{tabular}{c|c|c|c}
\hline & MSD & MSE & Valor de $\mathbf{p}$ \\
\hline GA1 & $2,21 \pm 0,15 \mathrm{~cm}$ & $2,35 \pm 0,10 \mathrm{~cm}$ & $\mathrm{p}=0,0890$ \\
\hline $\mathbf{G A 2}$ & $2,30 \pm 0,12 \mathrm{~cm}$ & $2,39 \pm 0,12 \mathrm{~cm}$ & $\mathrm{p}=0,0444^{*}$ \\
\hline $\mathbf{G A 3}$ & $2,22 \pm 0,09 \mathrm{~cm}$ & $2,27 \pm 0,11 \mathrm{~cm}$ & $\mathrm{p}=0,0075^{*}$ \\
\hline $\mathbf{G B 1}$ & $2,39 \pm 0,09 \mathrm{~cm}$ & $2,36 \pm 0,17 \mathrm{~cm}$ & $\mathrm{p}=0,5485$ \\
\hline $\mathbf{G B 2}$ & $2,37 \pm 0,07 \mathrm{~cm}$ & $2,28 \pm 0,10 \mathrm{~cm}$ & $\mathrm{p}=0,1667$ \\
\hline $\mathbf{G B 3}$ & $2,33 \pm 0,15 \mathrm{~cm}$ & $2,24 \pm 0,12 \mathrm{~cm}$ & $\mathrm{p}=0,1817$ \\
\hline GC & $2,35 \pm 0,14 \mathrm{~cm}$ & $2,42 \pm 0,15 \mathrm{~cm}$ & $\mathrm{p}=0,3264$ \\
\hline
\end{tabular}

* Diferença estatisticamente significativa.

\section{Estimativa de sarcômeros em série na fibra muscular}

Na estimativa de sarcômeros em série ao longo da fibra muscular, em nenhum grupo, ao comparar o lado direito com o esquerdo, foi observada diferença significativa (tabela 2).

Tabela 2. Resultados da estimativa de sarcômeros em série ao longo da fibra muscular, de acordo o grupo avaliado, comparando os valores do músculo sóleo direito (MSD) com os do músculo sóleo esquerdo (MSE)

\begin{tabular}{c|c|c|c}
\hline & MSD & MSE & Valor de $p$ \\
\hline GA1 & $5.453,00 \pm 609,30$ & $5.745,00 \pm 464,10$ & $p=0,4061$ \\
\hline GA2 & $5.713,00 \pm 387,20$ & $5.924,00 \pm 605,20$ & $p=0,3730$ \\
\hline GA3 & $4.695,00 \pm 1.059,00$ & $5.090,00 \pm 333,20$ & $p=0,4120$ \\
\hline GB1 & $5.796,00 \pm 433,00$ & $5.885,00 \pm 1.161,00$ & $p=0,8887$ \\
\hline GB2 & $6.287,00 \pm 487,40$ & $6.205,00 \pm 867,30$ & $p=0,8733$ \\
\hline GB3 & $5.863,00 \pm 505,50$ & $5.953,00 \pm 951,60$ & $p=0,8193$ \\
\hline GC & $3.879,00 \pm 689,20$ & $3.962,00 \pm 651,10$ & $p=0,8657$ \\
\hline
\end{tabular}

\section{Estimativa de sarcômeros em série ao longo do músculo}

Os valores para estimativa de sarcômeros em série não apresentaram, na comparação entre os sóleos direito e esquerdo, diferenças significativas (tabela 3).

Tabela 3. Resultados da estimativa de sarcômeros em série ao longo do músculo, de acordo o grupo avaliado, comparando os valores do músculo sóleo direito (MSD) com os do músculo sóleo esquerdo (MSE)

\begin{tabular}{c|c|c|c}
\hline & MSD & MSE & Valor de $p$ \\
\hline GA1 & $11.220,00 \pm 1.056,00$ & $12.460,00 \pm 725,30$ & $p=0,0948$ \\
\hline GA2 & $11.340,00 \pm 1.147,00$ & $11.770,00 \pm 1.017,00$ & $p=0,3802$ \\
\hline GA3 & $11.960,00 \pm 797,40$ & $12.460,00 \pm 1.183,00$ & $p=0,3553$ \\
\hline GB1 & $11.650,00 \pm 1.650,00$ & $11.480,00 \pm 1.246,00$ & $p=0,8119$ \\
\hline GB2 & $11.640,00 \pm 296,60$ & $11.060,00 \pm 735,20$ & $p=0,0585$ \\
\hline GB3 & $10.780,00 \pm 982,10$ & $10.910,00 \pm 1.067,00$ & $p=0,6436$ \\
\hline GC & $11.680,00 \pm 1.379,00$ & $11.690,00 \pm 1.095,00$ & $p=0,9704$ \\
\hline
\end{tabular}

\section{Estimativa do tamanho médio de sarcômeros}

Com relação à estimativa do tamanho de sarcômeros, novamente não se observou diferença significativa entre os lados direito e esquerdo (tabela 4).

Tabela 4. Resultados da média de comprimento de sarcômeros, de acordo o grupo avaliado, comparando os valores do músculo sóleo direito (MSD) com os do músculo sóleo esquerdo (MSE)

\begin{tabular}{c|c|c|c}
\hline & MSD & MSE & Valor de $p$ \\
\hline GA1 & $1,98 \pm 0,14 \mu \mathrm{m}$ & $1,89 \pm 0,06 \mu \mathrm{m}$ & $\mathrm{p}=0,2433$ \\
\hline GA2 & $2,04 \pm 0,18 \mu \mathrm{m}$ & $2,03 \pm 0,12 \mu \mathrm{m}$ & $\mathrm{p}=0,8990$ \\
\hline GA3 & $1,92 \pm 0,06 \mu \mathrm{m}$ & $1,86 \pm 0,13 \mu \mathrm{m}$ & $\mathrm{p}=0,4025$ \\
\hline GB1 & $2,08 \pm 0,25 \mu \mathrm{m}$ & $2,07 \pm 0,20 \mu \mathrm{m}$ & $\mathrm{p}=0,9592$ \\
\hline GB2 & $2,03 \pm 0,06 \mu \mathrm{m}$ & $2,07 \pm 0,13 \mu \mathrm{m}$ & $\mathrm{p}=0,6125$ \\
\hline GB3 & $2,17 \pm 0,17 \mu \mathrm{m}$ & $2,06 \pm 0,13 \mu \mathrm{m}$ & $\mathrm{p}=0,0821$ \\
\hline GC & $2,08 \pm 0,15 \mu \mathrm{m}$ & $2,02 \pm 0,14 \mu \mathrm{m}$ & $\mathrm{p}=0,3309$ \\
\hline
\end{tabular}

\section{DISCUSSÃO}

Dentre as técnicas para ganhos de flexibilidade, o alongamento estático tem- se tornado o método mais amplamente utilizado para ganho de ADM, por causa de sua simplicidade de execução e menor potencial para trauma tecidual ${ }^{(18)}$. Por isso, foi investigado em diversos trabalhos e aconselhados tempos próximos a 30s de manutenção do estresse de alongamento ${ }^{(19)}$, semelhante àquele utilizado no presente estudo. Também se adotou um período de três semanas de alongamento, pois Brucker et al.(20), em indivíduos saudáveis, utilizaram protocolo semelhante com relação ao tempo, ou seja, cinco dias por semana, com exclusão dos finais de semana, e observaram ganhos significativos na extensibilidade muscular.

A imobilização em posição alongada ou longos períodos de alongamento propiciam alterações no tecido contrátil, com aumento no comprimento de miofibras por adição de novos sarcômeros em série(21). Para Caiozzo et al.(22), a sarcomerogênese pode não ocorrer até o comprimento do sarcômero exceder um determinado ponto; uma vez além, alguma resposta celular e/ou molecular poderia produzir aumento no número de sarcômeros em série, retornando o comprimento do sarcômero ao apropriado. No presente estudo não foram observadas diferenças com relação ao tamanho dos sarcômeros, entre os lados direito e esquerdo para nenhum grupo avaliado; isso indica que o tamanho dos sarcômeros apontou para a funcionalidade muscular.

Koh ${ }^{(23)}$ relata que um músculo pode adicionar ou remover sarcômeros em série, para ajustar o comprimento em direção ao ângulo articular ótimo, no qual a força muscular máxima é produzida durante o treinamento. Tal adaptação poderia ser consistente com a hipótese de força máxima de regulação de número de sarcômeros ${ }^{(24)}$. No presente estudo, os animais não tiveram aumento de sarcômeros em série ao longo da fibra ou do músculo, pois, apenas durante um pequeno período de tempo eram estimulados para adição de sarcômeros, e na maior parte do dia continuavam com suas atividades normais, ou seja, em ângulo articular diferente daquele estimulado pelo alongamento.

Devido ao fato observado, por meio de eletromiografia, que o músculo sóleo no rato é ativo durante todo o tempo em que o animal está em pé(25), vê-se que a ativação do mesmo ocorre durante períodos prolongados. Tal fato pode impedir que estimulação em curtos períodos, como no presente estudo, altere as características morfológicas longitudinais do músculo, tendo implicações para o uso do alongamento de curta duração, tanto para a terapêutica quanto para o treinamento físico. 
O efeito do alongamento e adaptação a um comprimento funcional aumentado é associado a síntese proteica aumentada(26) Visto que, uma das características do ultrassom terapêutico é o incremento na síntese proteica(27), pesquisou-se no presente estudo se a adição do ultrassom em doses terapêuticas ao tecido muscular sob alongamento poderia aumentar a expressão proteica e elevar o conteúdo de sarcômeros em série e em paralelo, o que seria refletido em aumento no comprimento muscular. Contudo, tais fatos não foram observados aqui, visto que apenas o comprimento muscular foi maior nos músculos tratados com ultrassom em doses térmicas, mas sem adição significativa de sarcômeros em série.

O ultrassom, quando usado terapeuticamente, é similar à diatermia em muitos aspectos; ele pode aquecer tecidos em profundidades de 3 a $5 \mathrm{~cm}$ ou mais ${ }^{(28)}$; e, também, é frequentemente usado devido a seus efeitos não térmicos, que incluem cavitação estável, a qual pode resultar em alterações difusionais ao longo das membranas celulares, e correnteza acústica, que aumenta a permeabilidade da membrana e parede vascular. Contudo, quando se deseja aumento de temperatura tecidual, o tratamento com ultrassom deve ser realizado por ao menos 5 min, e não deve cobrir área maior do que duas a três vezes o tamanho da ERA, visto que quando a extensão da área de tratamento aumenta, a taxa de aquecimento diminui ${ }^{(29)}$. No presente estudo empreendeu-se tal metodologia, visto que a área tratada nos animais foi de aproximadamente $1 \mathrm{~cm}^{2}$, semelhante à ERA do equipamento utilizado, e o tempo de tratamento foi de $5 \mathrm{~min}$.

Wessling et al. ${ }^{(12)}$ demonstraram, em humanos, que a combinação do alongamento estático e ultrassom térmico aumenta a extensibilidade do músculo tríceps sural, além do alcançado pelo alongamento apenas. Knight et al. ${ }^{(13)}$, de forma concordante, observaram que o ultrassom foi mais efetivo no aumento do arco ativo e passivo de movimento, ao comparar com outras formas de aquecimento. Costa et al. ${ }^{(14)}$ relatam que o ultrassom produz aumento de temperatura nas estruturas musculares, proporcionando relaxamento muscular e alteração na viscoelasticidade, o que explica o ganho adicional de ADM, ao submeter esse grupo muscular a alongamento estático. Tal característica pode ser observada também no presente estudo, visto que para os grupos em que foram utilizadas doses térmicas do ultrassom, observaram-se ganhos significativos no comprimento dos mesmos, ao comparar com o lado contralateral.
Draper et al. ${ }^{(30)}$ observaram que o equipamento de $1 \mathrm{MHz}$ é capaz de produzir aumentos na temperatura superiores a $3^{\circ} \mathrm{C}$, o que induziria alterações viscoelásticas do colágeno, quando os tecidos sofrem a maior extensibilidade e alongamento, denominado "janela de alongamento". Rose et al.(28) relatam que a "janela de alongamento" para equipamentos operando em $1 \mathrm{MHz}$ tem maior tempo do que aquela observada para $3 \mathrm{MHz}$, sendo de aproximadamente $3 \mathrm{~min}$. O período de janela de alongamento foi respeitado no presente estudo, visto que logo ao final da aplicação do ultrassom terapêutico iniciava-se o alongamento, e mesmo com os períodos de repouso, entre cada alongamento, o tempo máximo era de 2 min e 30s. Dessa forma, o aquecimento produzido com 1,0 e 0,5W/cm², que são doses consideradas térmicas ${ }^{(11)}$, conduziu à "janela de alongamento"; com isso explica-se o resultado obtido no comprimento muscular, maior para os músculos alongados nesses grupos. Além disso, a ausência de outros efeitos longitudinais nos músculos, como o aumento de sarcômeros em série, não significa que não houve alteração na extensibilidade tecidual, a qual pode ter ocorrido por alterações nas isoformas de titina, nas características do tecido conectivo muscular e no aumento da tolerância ao alongamento(31), características que podem ser entendidas como limitações do estudo e que não foram analisadas aqui. Também, deve-se levar em conta que o presente trabalho foi realizado em animais, havendo necessidade de futuramente replicação desse tipo de estudo em humanos.

\section{CONCLUSÃO}

De acordo com a metodologia aplicada e os resultados encontrados neste estudo, conclui-se que o alongamento passivo estático e o uso associado do ultrassom terapêutico, de forma térmica, produziram alterações apenas no comprimento muscular em repouso, o qual foi aumentado; para as outras variáveis analisadas (comprimento de sarcômero, estimativa de sarcômeros em série ao longo da fibra e do músculo), não houve efeitos dessa forma terapêutica.

Todos os autores declararam não haver qualquer potencial conflito de interesses referente a este artigo.

\section{REFERÊNCIAS BIBLIOGRÁFICAS}

1. Tricoli V, Paulo AC. Efeito agudo dos exercícios de alongamento sobre o desempenho de força máxima. Rev Bras Ativ Fís Saúde. 2002;7:6-10.

2. Durigon OFS. O alongamento muscular. Rev Fisiot USP. 1995;2:40-4.

3. Thacker SB, Gilchrist J, Stroup DF, Kimsey CD. The impact of stretching on sports injury risk: a systematic review of the literature. Med Sci Sports Exerc. 2004;36(3):371-8.

4. Shrier I. Does stretching improve performance? A systematic and critical review of the literature. Clin J Sport Med. 2004;14(5):267-73.

5. Feland JB, Myrer JW, Schulthies SS, Fellingham GW, Measom GW. The effect of duration of stretching of the hamstring muscle group for increasing range of motion in people age 65 years or older. Phys Ther. 2001;81(5):1110-7.

6. Chan SP, Hong Y, Robinson PD. Flexibility and passive resistance of the hamstrings of young adults using two different static stretching protocols. Scand J Med Sci Sports. 2001;11(2):81-6.

7. Deyne P. Application of passive stretch and its implications for muscle fibers. Phys Ther. 2001;81(2):819-26.

8. Ter Haar G. Therapeutic ultrasound. Eur J Ultrasound. 1999;9(1):3-9.

9. Starkey C, editor. Recursos terapêuticos em fisioterapia. São Paulo: Manole, 2001.

10. Young S. Terapia com ultra-som. In: Kitchen S, editor. Eletroterapia: prática baseada em evidências. Barueri: Manole, 2003;211-30.

11. Johns LD. Nonthermal effects of therapeutic ultrasound: the frequency resonance hypothesis. J Athl Train. 2002;37(3):293-9.

12. Wessling KC, Devane DA, Hylton CR. Effects of static stretch versus static stretch and ultrasound combined on triceps surae muscle extensibility in healthy women. Phys Ther. 1987;67(5):674-9.

13. Knight CA, Rutledge CR, Cox ME, Acosta M, Hall SJ. Effect of superficial heat, deep heat, and active exercise warm-up on the extensibility of the plantar flexors. Phys Ther. 2001;81(6):1206-14.

14. Costa LOP, Costa LCM, Mendes PL, Cançado RL, Lara KL, Lima MD, et al. Efeitos do aquecimento por ultra-som e atividade física aeróbica na flexibilidade do tríceps sural humano - um estudo comparativo. Fisiot Mov. 2006;19(2):19-24

15. Andersen ML, D'Almeida V, Ko GM, Kawakami R, Martins PJF, Magalhães LE, et al. Princípios éticos e práticos do uso de animais de experimentação. São Paulo: UNIFESP, 2004.

16. Demmink JH, Helders PJM. The effect of moving an ultrasound transducer on tissue heating. Adv Physiother. 2003;5(2):50-6.

17. Konno EAB, Alves ÉPB, Bertolini GRF, Barbieri CH, Mazzer N. Remobilização por alongamento estático cíclico em sóleo de ratos imobilizados em encurtamento. Rev Bras Med Esporte. 2008; no prelo.

18. Roberts JM, Wilson K. Effect of stretching duration on active and passive range of motion in the lower extremity. Br J Sports Med. 1999;33(4):259-63.

19. Nelson RT, Bandy WD. Eccentric Training and Static Stretching Improve Hamstring Flexibility of High School Males. J Athl Train. 2004;39(3):254-8.

20. Brucker JB, Knight KL, Rubley MD, Draper DO. An 18-day stretching regimen, with or without pulsed, shortwave diathermy, and ankle dorsiflexion after 3 weeks. J Athl Train. 2005;40(4):276-80.

21. Goldspink DF, Cox VM, Smith SK, Eaves LA, Osbaldeston NJ, Lee DM, et al. Muscle growth in response to mechanical stimuli. Am J Physiol. 1995;268(2):E288-97.

22. Caiozzo VJ, Utkan A, Chou R, Khalafi A, Chandra H, Baker M, et al. Effects of distraction on muscle length: mechanisms involved in sarcomerogenesis. Clin Orthop Relat Res. 2002;403S:S133-45.

23. Koh TJ. Do adaptations in serial sarcomere number occur with strength training? Hum Mov Sci. 1995;14(1):61-77.

24. Goldspink G. Changes in muscle mass and phenotype and the expression of autocrine and systemic growth factors by muscle in response to stretch and overload. J Anat. 1999;194:323-34.

25. Goldspink G, Scutt A, Loughna PT, Wells DJ, Jaenicke T, Gerlach GF. Gene expression in skeletal muscle in response to stretch and force generation. Am J Physiol. 1992;262(3):R356-63.

26. Goldspink G. Gene expression in muscle in response to exercise. J Muscle Res Cell Motil. 2003;24(2-3):121-6.

27. Yang RS, Chen YZ, Huang TH, Tang CH, Fu WM, Lu BY, et al. The effects of low-intensity ultrasound on growing bone after sciatic neurectomy. Ultrasound Med Biol. 2005;31(3):431-7.

28. Rose S, Draper DO, Schulthies SS, Durrant E. The stretching window part two: rate of thermal decay in deep muscle following 1-MHz ultrasound. J Athl Train. 1996;31(2):139-43.

29. Garret CL, Draper DO, Knight KL. Heat distribution in the lower leg from pulsed short-wave diathermy and ultrasound treatments. J Athl Train. 2000;35(1):50-5.

30. Draper DO, Harris ST, Schulthies S, Durrant E, Knight KL, Ricard M. Hot-pack and 1-MHz ultrasound treatments have an additive effect on muscle temperature increase. J Athl Train. 1998;33(1):21-4.

31. Lardner R. Stretching and flexibility: its importance in rehabilitation. J Bodywork Mov Ther. 2001;5(4):254-63. 